\title{
MAXIMAL OXYGEN UPTAKE AND BLOOD LIPIDS*
}

\author{
HENRY J. MONTOYE, WALTER D. BLOCK and \\ RICHARD GAYLE \\ University of Wisconsin, Madison, Wisconsin \\ University of Michigan Medical Center, and School of Public Health, Ann Arbor, Michigan \\ University of Tennessee, Knoxville, TN, U.S.A.
}

(Received in revised form 14 July 1977)

\begin{abstract}
One thousand and sixty males and 119 females age $10-69$, were tested on the treadmill as they walked at $3 \mathrm{mph}$ ( $2 \mathrm{mph}$ in subjects $60 \mathrm{yr}$ and older). Every $3 \mathrm{~min}$, the grade was increased $3 \%$. Uxygen uptake and related measurements were recorded during the $3 \mathrm{rd} \mathrm{min}$ at each grade. Subjects, age 10-39, exercised to exhaustion and maximal oxygen uptake ( $\mathrm{VO}_{2}$ max) was measured. In subjects age 40-69, $\mathrm{VO}_{2} \max$ was estimated from sub-max $\mathrm{VO}_{2}$ and heart rate. Serum cholesterol and serum triglyceride were determined in most of these subjects. After removing the effects of age, wt and sum of four skinfolds, nonfasting values of cholesterol and triglyceride concentrations were unrelated to $\mathrm{VO}_{2} \max$.
\end{abstract}

\section{INTRODUCTION}

Serum concentrations of cholesterol and triglycerides are recognized as being related to the development of coronary heart disease. It has been thought that habitual physical activity and physical fitness for muscular work might be related to the blood concentration of these lipids. The Tecumseh, Michigan Community Health Study afforded an opportunity to study these relationships. In two previous examinations in the Tecumseh population (1959-1960 and 1961-1965) neither maximal oxygen uptake ( $\dot{\mathrm{V} O} \mathrm{O}_{2} \max$ ) nor maximal work capacity was measured. However, these measurements were taken in some of the residents of Tecumseh during the third series of examinations (1967-1969). It is difficult to measure habitual physical activity accurately. Since exercise training is known to increase $\mathrm{V}_{2}$ max some believe the relationship of exercise habits to serum lipids might better be studied by using the more objective measure of $\dot{\mathrm{V}}_{2}$ max. Also, it is well known that exercise increases the mobilization of free fatty acids for energy [1-4]. Gordon [5] has even suggested that the generation of DPNH in striated muscle, which appears to suppress cholesterol synthesis, may lower cholesterol in the blood. Because of these observations, it appeared important to study the relationship of blood lipids to $\dot{\mathrm{V}}_{2}$ max and maximal performance on a treadmill test.

The relationship between the concentration of cholesterol and triglycerides in blood serum on the one hand, and habitual activity on the other, has been summarized recently [6]. The present report contains an analysis of the relationship of these blood lipids to $\mathrm{V}_{2}$ max in respondents in the Tecumseh, Michigan Community Health Study.

\section{Subjects}

METHODS

The Tecumseh Community Health Study has been described briefly in this journal [6] and in detail elsewhere [7]. It is an ecologic investigation of a community of about 10,000 persons. The genetic influences and the biological, physical, and social environment are being studied with a view to determine how these factors interact to enable some individuals to maintain health while others become susceptive to disease.

\footnotetext{
*Supported in part from a grant from the Graduate School, University of Wisconsin; NIH Grant HE 14712; and the Center for Research in Diseases of the Heart, Circulation and Related Disorders, University of Michigan, under Program Project Grant HE 09814. The technical assistance of David A. Cunningham, Mary E. Frantz, Elaine Dempsey and Carolyn Carpenter are gratefully acknowledged.
} 
The third series of examinations (1967-1969) was limited to:

(1) persons who have been previously examined at least once and

(2) persons of all ages, whether previously examined or not, who were residing in a $10 \%$ random sampling of dwelling units. It was not possible to obtain treadmill test data on all these respondents. The decision was, therefore, made to give a treadmill test to medically eligible subjects as follows: (a) males and females, age 10-69, in the $10 \%$ random sample (b) all males previously examined who were age $35-69$, and (c) males age 10-34 in a small group of special subjects described elsewhere [7, p.5]. The first task was to compare the treadmill data in the $10 \%$ random sample, which was selected to be representative of the entire community, with the subjects in (b) and (c). There were no important differences so the addition of subjects in (b) and (c) did not alter the representativeness of the sample taking the treadmill test. Among all subjects defined above, who were medically eligible to take the treadmill test, $83 \%$ of the males and $59 \%$ of the females actually took the test. Medical criteria for excluding subjects from the exercise test have been published [7, p.51].

\section{Treadmill test}

The detailed procedures of the treadmill test have been published $[7,8]$. Briefly, the test employed by us consists of walking on the treadmill at $4.83 \mathrm{~km}$ ( 3.0 miles) per $\mathrm{hr}$ at zero grade for $3 \mathrm{~min}$; thereafter, the mill is raised $3 \%$ every $3 \mathrm{~min}$ with speed maintained. In subjects 60 years of age, and on rare occasions in younger subjects, the speed is maintained at $3.27 \mathrm{~km}$ ( 2.0 miles) per hr. The percent grade is calculated as the height over the belt travel (sine of the angle), not the rise over the run (tangent of the angle) as defined in engineering terms.

The electrocardiogram, heart rate, ventilation and percent oxygen and carbon dioxide were recorded on an $\mathrm{E}$ for $\mathrm{M}$ 8-channel-recorder. Ventilation was measured with a D-4 or CD-4 Parkinson Cowan dry gas meter. The exhaled air was led into a mixing chamber and a sample pumped through a Beckman model F3 oxygen analyzer and a Capnograph $\left(\mathrm{CO}_{2}\right.$ analyzer). Although the data were recorded continuously, only data for the last minute at each treadmill grade were usually utilized. A sample of exhaled air was taken for micro-Scholander analysis on approximately every fifth subject. The accuracy of the electronic meters was highly satisfactory [8].

Criteria for stopping the exercise by the attending physician were agreed upon before the exercise tests in Tecumseh were initiated. These included certain symptoms and physical and electrocardiographic signs $[7,8]$. If the exercise was not terminated by the physician, the end point of the exercise was the subject's own estimate of exhaustion, if he or she was $10-39 \mathrm{yr}$. For subjects $40-59 \mathrm{yr}$, the test was terminated when the heart rate reached 160 . For subjects $60-69 \mathrm{yr}$, the test was terminated at a heart rate of 150. In the older age groups (40-69), if the subject felt exhausted and could not continue the exercise, the test was terminated even though the specified heart rate had not been reached.

Despite encouragement, a few subjects seemed unwilling to exercise to exhaustion. This was a subjective evaluation made at the time of the test by the investigators. These few cases were coded "uncooperative." There were also a few instances when the respondent terminated the test because of leg cramps rather than general exhaustion and this was noted at the time of the test. The total numbers of subjects in these two categories were 21 males and 7 females. Also, in 9 instances, the test could not be completed because of equipment difficulties. For the most part, these were cases in which a good ECG could not be obtained.

For subjects who terminated the exercise because of exhaustion, $\dot{\mathrm{VO}}_{2} \max$ was the actually measured maximal oxygen uptake. This included almost all subjects below $40 \mathrm{yr}$ and a few beyond this age. For subjects $40 \mathrm{yr}$ and above who did not reach exhaustion (for example, those who were stopped because of reaching a heart rate of 160) their $\dot{\mathrm{VO}}_{2}$ max was predicted. This was done by fitting a straight line to measured 
TABLE 1. REASONS FOR EXCLUSIONS OF SUBJECTS FROM STATISTICAL ANALYSES

\begin{tabular}{lcc}
\hline & Males & Females \\
\hline $\begin{array}{l}\text { Number given treadmill test } \\
\text { Number over 40 yr for whom }\end{array}$ & 1060 & 119 \\
VO $_{2}$ max could not be predicted* & 152 & 21 \\
$\begin{array}{l}\text { Number for whom no blood data } \\
\text { and/or skinfolds was available }\end{array}$ & 81 & 15 \\
$\begin{array}{l}\text { Number with complete data } \\
\text { *These include subjects with significant ECG changes, }\end{array}$ \\
$\begin{array}{l}\text { equipment problems, insufficient heart rate-oxygen } \\
\text { uptake values to accurately predict VO } \\
\text { few who were uncooperative or who developed leg } \\
\text { cramps. }\end{array}$
\end{tabular}

submaximal oxygen uptake-heart rate points, and extrapolating to the estimated maximal heart rate for the subject's age. The estimated maximum heart rate was derived from a regression line based on the published maximum heart rates for males and females. There were several restrictions placed on this procedure. No $\dot{\mathrm{VO}}_{2} \max$ was predicted if it was necessary to extrapolate beyond twenty heart beats. Also, unless there was a minimum of three oxygen uptake-heart rate points, $\dot{\mathrm{V}} \mathrm{O}_{2} \max$ was not predicted. Thus, no $\mathrm{VO}_{2} \max$ was available in some of the subjects; for example, those whose test was terminated early because of significant ECG changes. The numbers of subjects with complete treadmill and other data were 827 males and 83 females. Table 1 contains an explanation for the exclusion of some of the subjects from the statistical analysis.

\section{Blood lipids}

Usually within a week, but not more than 5 weeks, before the treadmill test was administered, the respondents came to the clinic, ordinarily in family groups. At this time, height, weight, and skinfolds were measured and a blood sample was drawn. Insofar as the blood analyses were concerned most of the respondents were not in a post absorptive state. Serum total cholesterol was determined on the autoanalyzer by the method of Block et al. [9]. Serum triglycerides were done on the autoanalyzer by the Kessler method as modified by Block and Jarrett [10]. The day-to-day within individual variations in cholesterol and triglycerides was about 6 and $8 \%$, respectively. The blood analyses were done in the laboratory of one of the co-authors (W.D.B.). This is one of the laboratories standardized by the Center for Disease Control in Atlanta.

\section{Body fatness}

Skinfolds were measured at four sites: namely, triceps, subscapula, suprailium and adjacent to the umbilicus. The measurements were taken with a Lange caliper which was calibrated by means of small springs of known force-compression curves. The measure of body fatness was simply the sum of the four skinfolds.

\section{Distributions}

Before the data were analyzed, all treadmill, lipid and skinfold distributions were studied. All of the variables, with the exception of triglycerides and sum of skinfolds, closely approximated the normal distribution. Triglycerides were markedly positively skewed and skinfolds were only slightly positively skewed.

\section{RESULTS}

\section{Serum cholesterol}

The usual approach in analyzing the data would be to correlate $\mathrm{VO}_{2} \max (\mathrm{ml} / \mathrm{kg}$ body $\mathrm{wt} / \mathrm{min}$ ) with serum cholesterol and triglycerides. This essentially eliminates the effect of body wt on $\mathrm{VO}_{2} \max$ as measured in liters per min. These correlation coeff- 
Table 2. Partial correlation coefficients: SERUM TOTAL CHOLESTEROL VS $\mathrm{VO}_{2} \max$ (EFFECTS OF $\triangle$ GE, WEIGHT AND SKINFOLDS REMOVED)

\begin{tabular}{|c|c|c|c|c|}
\hline $\begin{array}{l}\text { Age } \\
\text { group }\end{array}$ & $N$ & $\begin{array}{l}\text { les } \\
\text { Partial } \\
\text { correlation } \\
\text { coefficient* }\end{array}$ & $N$ & $\begin{array}{l}\text { Females } \\
\text { Partial } \\
\text { correlation } \\
\text { coefficient* }\end{array}$ \\
\hline $10-19$ & 285 & 0.08 & 44 & -0.06 \\
\hline $20-29$ & 103 & -0.14 & 15 & -0.21 \\
\hline $30-39$ & 189 & 0.00 & 16 & 0.04 \\
\hline $40 \quad 49$ & 189 & -0.12 & & \\
\hline $50-59$ & 53 & -0.09 & 8 & -0.54 \\
\hline $60-69$ & 8 & 0.40 & & \\
\hline $10-69$ & 827 & -0.08 & 83 & -0.17 \\
\hline
\end{tabular}

*None of the correlation coefficients was statistically significant, $\mathbf{P}<0.01$.

cients were calculated for our data. For males, $\mathrm{VO}_{2} \max$ is significantly related to serum cholesterol and triglycerides with the males with the higher $\dot{\mathrm{VO}}_{2}$ max having the lower lipid values. The relationships are in the same direction for females and in the case of $\mathrm{VO}_{2}$ max and cholesterol the coefficient is statistically significant. However, blood lipids are positively related to both age and skinfolds, whereas $\mathrm{VO}_{2} \max$ is negatively related to age and skinfolds. Therefore, the $\mathrm{V}_{2}$ max-blood lipid correlations may only reflect the influence of age and body fatness.

Partial correlation coefficients were therefore calculated to study the relationship between blood lipids and $\mathrm{V}_{2} \max (1 / \mathrm{min})$ with the influence of age, wt and skinfolds removed by multiple regression. The relationship between age and $\dot{\mathrm{V}}_{2} \max$ is not linear over the entire age range. However, within the narrow age ranges we used, the deviation for linearity is insignificant. The results of this analysis for serum total cholesterol appears in Table 2 . None of the partial correlation coefficients are statistically

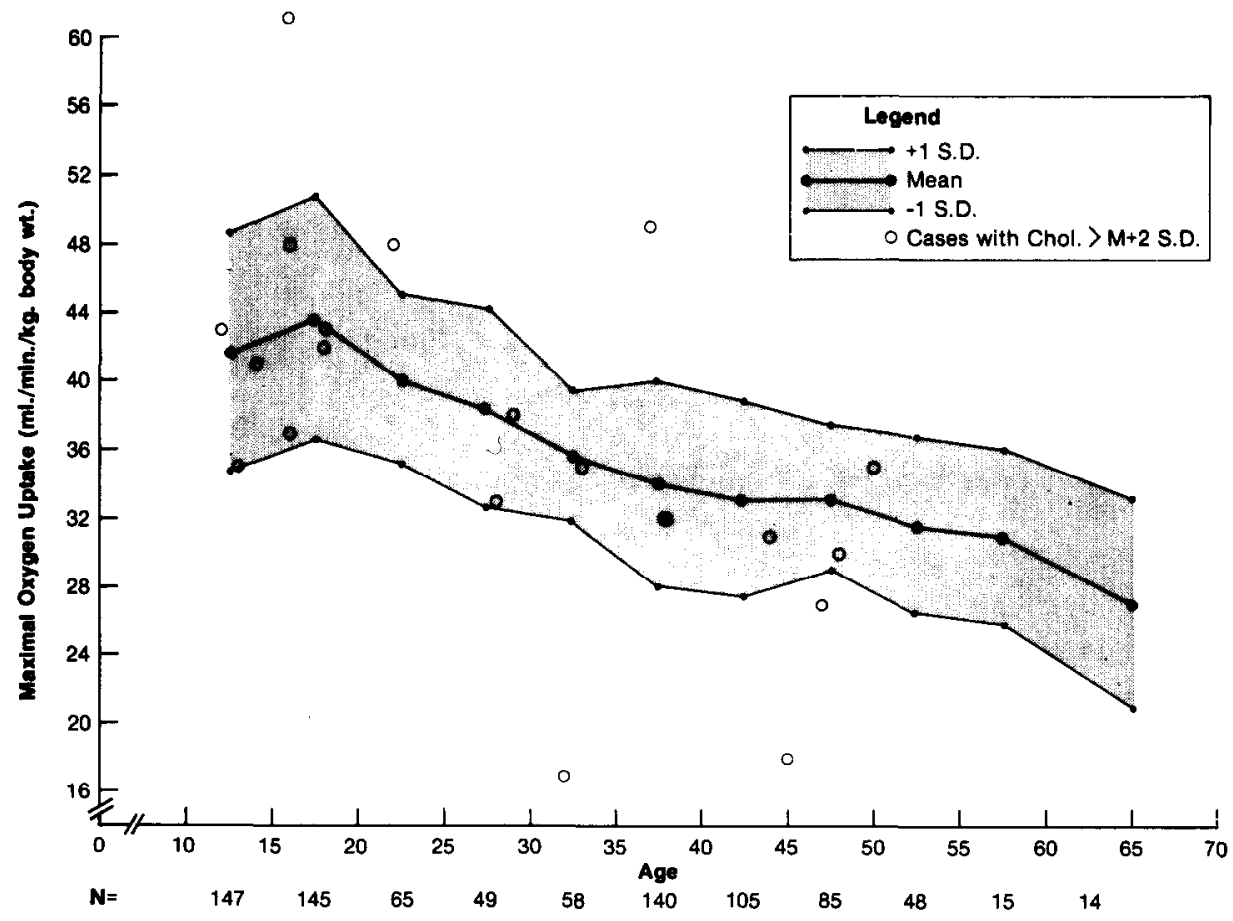

FIG. 1. Maximal oxygen uptake of subjects with high serum total cholesterol compared to $\mathrm{VO}_{2} \max$ for the rest of the population. Numbers of subjects listed below were used to calculate means and S.D. for $\mathrm{VO}_{2} \max$ and exclude high cholesterol subjects. 


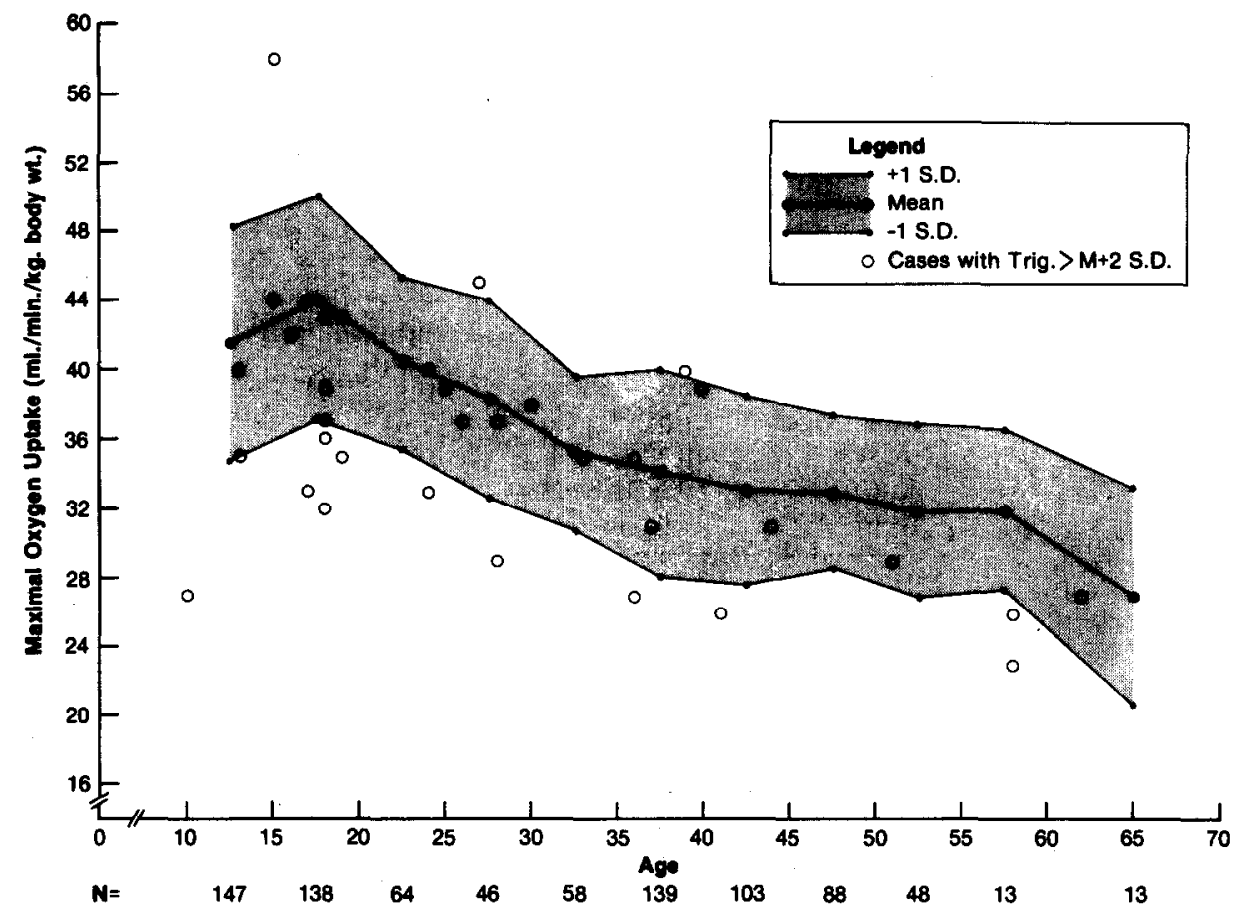

Fig. 2. Maximal oxygen uptake of subjects with high serum triglycerides compared to $\mathrm{VO}_{2} \mathrm{max}$ for the rest of the population. Numbers of subjects listed below were used to calculate means and S.D. for $\mathrm{VO}_{2} \max$ and exclude high triglycerides subjects.

significant. It is possible that $\dot{\mathrm{VO}}_{2} \max$ and serum cholesterol are related at only one end of the distribution. The $\dot{\mathrm{VO}}_{2} \max$ of those male subjects whose cholesterol was more than two standard deviations (S.D.) above the mean is compared with the rest of the population in Fig. 1. There is no indication that the $\dot{\mathrm{V}}_{2} \max$ of males with high cholesterol is different from other subjects.

The results in Table 2 are based on all subjects for whom blood lipids and treadmill performance data were available. One can hypothesize that if data from only the subjects who exercised to exhaustion were included, the relationship between serum cholesterol and $\dot{\mathrm{V}}_{2}$ max might be stronger. This did not prove to be the case. When the analyses were repeated using (1) total sample excluding subjects who were uncooperative or complained of leg cramps, and (2) only those subjects who exercised to exhaustion, the partial correlation coefficients for the modified samples are virtually identical to those for the total sample (i.e. those in Table 2).

\section{Serum triglycerides}

Partial correlation coefficients similar to those in Table 2 were calculated for non-fasting serum triglycerides. As before, the influence of age, wt, skinfolds was removed by regression analysis. The results appear in Table 3. There is essentially no correlation between non-fasting serum triglycerides and $\mathrm{VO}_{2}$ max. The $\dot{\mathrm{VO}}_{2} \max$ of subjects whose triglycerides were more than two S.D. above the mean are compared to the rest of the population in Fig. 2. There is a tendency for the high triglyceride subjects to have slightly lower $\dot{\mathrm{V}} \mathrm{O}_{2}$ max. $\dot{\mathrm{V}} \mathrm{O}_{2} \max$ is expressed per unit body wt, which climinates the effect of body wt, but not the effect of body fatness. Therefore, the skinfold values of these same high triglycerides were plotted against the mean and S.D. of the rest of the population as in Figs. 1 and 2. Almost all of these subjects whose $\mathrm{VO}_{2} \max$ was low also were fatter than average. Hence the slight tendency for the $\dot{\mathrm{VO}}_{2} \max$ of high triglyceride subjects can be explained by their greater fatness.

As in the cholesterol analysis, partial correlation coefficients were calculated for modified samples. Again, the results for the modified samples are virtually the same as those for the total sample. 
Table 3. Partial correlation coefficients: SERUM TOTAL TRIGLYCERIDES VS $\dot{\mathrm{VO}}_{2} \max$ (EFFECTS OF AGE, WEIGHT AND SUM OF SKINFOLDS REMOVED)

\begin{tabular}{|c|c|c|c|c|}
\hline $\begin{array}{l}\text { Age } \\
\text { group }\end{array}$ & $N$ & $\begin{array}{l}\text { les } \\
\text { Partial } \\
\text { correlation } \\
\text { coefficient* }\end{array}$ & $N$ & $\begin{array}{l}\text { Females } \\
\text { Partial } \\
\text { correlation } \\
\text { coefficient* }\end{array}$ \\
\hline $10-19$ & 285 & 0.05 & 44 & -0.05 \\
\hline $20-29$ & 103 & -0.01 & 15 & 0.18 \\
\hline $30-39$ & 189 & -0.11 & 16 & 0.05 \\
\hline $40-49$ & 189 & -0.06 & & \\
\hline $50-59$ & 53 & -0.23 & 8 & 0.09 \\
\hline $60-69$ & 8 & 0.21 & & \\
\hline $10-69$ & 827 & -0.05 & 83 & -0.05 \\
\hline
\end{tabular}

* None of the correlation coefficients was statistically significant, $\mathbf{P}<0.01$.

There is another problem in analyzing the triglycerides data. The distribution of serum triglycerides is positively skewed, as pointed out earlier. It is possible for this to affect the correlation coefficient. Therefore, the nonparametric Kendall Rank Correlation Coefficient (or tau) was calculated in place of the Pearson Correlation Coefficient whenever triglycerides were involved [11]. Additionally, Kendall Partial Rank Correlation Coefficients were computed for the non-fasting serum triglycerides relationships. The calculation of tau does not require a normal or even symmetrical distribution. These analyses produced values for tau and partial tau almost identical to the $r$ and partial $r$ values.

\section{DISCUSSION}

It would have been desirable to obtain fasting rather than casual blood samples. Probably this would not have changed the serum cholesterol relationships. However, food consumed in the hours before the blood sample was obtained can be expected to affect the concentration of chylomicrons in the blood, and hence perhaps the triglycerides concentration since chylomicrons contain mostly triglycerides. The laboratory procedures were such that it is unlikely that any meal was consumed more recently than $2 \mathrm{hr}$ beforehand.

Table 4 contains a summary of previous reports in which the relation of serum total cholesterol concentration and work capacity have been studied. $\dot{\mathrm{V}}_{2}$ max was measured in these investigations. Shane [16] reported a low but statistically significant correlation coefficient $(-0.20)$ between work capacity on a treadmill and serum cholesterol but the effects of age and body fatness were not removed. In two other similar treadmill studies $[17,18]$ no correlation between work capacity and serum cholesterol was observed. On the other hand, Cooper et al. [19] reported lower serum cholesterol in men whose treadmill performance was excellent compared to those rated "very poor." The difference, after adjusting for height, wt, age and body fitness, was only $9 \mathrm{mg} \%$ !!

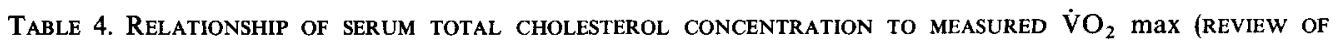
PREVIOUS STUDIES)

\begin{tabular}{|c|c|c|c|}
\hline Population & $\begin{array}{l}\text { Relationship of } \\
\text { cholesterol to } \dot{\mathrm{V}}_{2} \max \end{array}$ & $\begin{array}{l}\text { Other } \\
\text { factors }\end{array}$ & Reference \\
\hline $\begin{array}{l}11 \text { Soccer players } \\
19 \text { Medical students }\end{array}$ & $\begin{array}{l}\text { N.R. } \\
\text { N.R. }\end{array}$ & & $\begin{array}{l}\text { Nayman et al. [12] } \\
\text { Akgun [13] }\end{array}$ \\
\hline 86 Males age $40-69$ & N.R. & $\begin{array}{l}\text { Effect of age, fatness and } \\
\text { other variables removed }\end{array}$ & $\begin{array}{l}\text { McDonough } \\
\text { et al. }[14]\end{array}$ \\
\hline 531 Males age 54* & N.R. & & Grimby et al. [15] \\
\hline
\end{tabular}

*In some cases $\dot{\mathrm{V}} \mathrm{O}_{2}$ max was estimated rather than measured.

N.R. $=$ not related. 
Similarly, there was little or no correlation between serum cholesterol and work performance on a bicycle ergometer $[20,21]$. In another report [22] time required to run 1.5 miles was related to serum cholesterol $(r=0.30)$ but the relationship was not corrected for any influence of age and body fatness.

Heart rate response to a standard work task has often been employed as an estimate of work or metabolic capacity; low heart rates reflecting greater capacity. In a number of investigations, this estimate of fitness was studied in relation to serum cholesterol. The relationship, without adjusting for other factors such as age and fatness, was weak but statistically significant [21-28]. In other studies of this kind, when the influence of age and fatness were removed, the relationship of heart rate response to exercise (physical fitness) and serum cholesterol was statistically insignificant [29,30].

Oxygen uptake at a heart rate of 180 while exercising on a treadmill has also been used as an estimate of metabolic capacity. The correlation of this measurement with serum cholesterol was low and statistically significant $(r=-0.18)$ but again the relationship was not adjusted for the influence of age and body fatness [16].

Fifty middle-aged faculty members served as subjects in another study [31]. Their fitness was measured by scores on a number of tests including maximal oxygen uptake. When the most fit 12 men were compared with the least fit 12, there was no significant difference in serum cholesterol. On the other hand, Ekelund and Olsson [32], after correcting for age and wt, found that males with types IIA and IV hyperlipidaemia had lower work performance at a heart rate of 150 .

Clearly from our results and those of other investigators there is little evidence of a significant association between serum total cholesterol and fitness expressed as work capacity or measured or estimated $\mathrm{VO}_{2}$ max, provided that the influence of confounding variables is eliminated.

To our knowledge, serum concentration of triglycerides has not been previously studied in relation to measured $\dot{\mathrm{VO}}_{2}$ max, and only to a limited extent in relation to estimated $\mathrm{VO}_{2}$ max or work capacity. Oberman in 1965 in his Thousand Aviator Study [25] reported a statistically significant correlation between heart rate response to a modified Harvard Step Test and serum triglycerides in approximately 600 men, age 42-62. The coefficient was only 0.094 and probably would be even lower, if the effects of body fatness were eliminated. Two years later Allard et al. [20], reported a significant negative relationship between work accomplished on a bicycle ergometer at a heart rate of 150 and serum triglycerides. The relationship was weak and probably also contained the confounding effects of age and body fatness. Cooper et al. [19] reported large and statistically significant differences in serum triglycerides among males of different work capacity; high triglycerides concentrations being associated with poor work capacity. The relationships were adjusted for the influence of age, height, wt and body fatness and all of the men were in a postabsorptive state when blood was drawn. The subjects composed a self-selected population of predominantly high socio-economic level; hence, it is difficult to generalize to other populations.

In conclusion, it appears clear from our data and other studies that maximal oxygen uptake or work capacity is not significantly related to non-fasting serum cholesterol or triglycerides concentration. It is possible that had fasting blood samples been drawn the relationship of maximal oxygen uptake to serum triglycerides might have been different.

\section{REFERENCES}

1. Nikkilaea, Torsti P: Adjustment of fat metabolism to exercise as studied in vitro. Ch 19 in Karvonen MJ, Barry AJ (Eds) Physical Activity and the Heart. pp. 216-224, Springfield, Ill, CC Thomas: 1967

2. Konttinen A, Sarajas HSS, Frick MH, Rajasalmi M: Arteriovenous relationship of non-esterified fatty acids, triglycerides, cholesterol and phospholipids in exercise. Ann Med Exp Fenn. 40: 250-256, 1962

3. Konttinen A, Nikkila EA: Effect of acute exercise on serum triglycerides and free fatty acids. Ch 18 in Karvonen MJ, Barry AJ (Eds) Physical Activity and the Heart. pp. 208-215, Springfield, Ill, CC Thomas: 1967

4. Paul P: Effects of long lasting physical exercise and training in lipid metabolism. Howald $\mathbf{H}$, Poortmans JR (Eds) Metabolic Adaptation to Prolonged Physical Exercise. pp. 156-193, Basel, Birkhauser Verlag, 1975 
5. Gordon ES: The effect of exercise on lipid metabolism. Ch Il in Exercise and Fitness pp. 96-109, Chicago, Athletic Institute, 1960

6. Montoye HJ, Block WD, Metzner HL, Keller JB: Habitual physical activity and serum lipids: males, age 16-64 in a total community. J Chron Dis 29: 697-709, 1976

7. Montoye HJ : Physical Activity and Health: An Epidemiologic Study of an Entire Community. Englewood Cliffs, NJ: Prentice-Hall, Inc, 1975

8. Montoye HJ, Cunningham DA, Welch HG, Epstein FH: Laboratory methods of assessing metabolic capacity in a large epidemiological study. Am J Epid 91: 38-47, 1970

9. Block WD, Jarrett J, Levine JB: An improved automated determination of serum total cholesterol with a single color reagent. Clin Chem 12:681-685, 1966

10. Block WD, Jarrett $\mathrm{J} J \mathrm{r}$ : An automated technique for the quantitative determination of serum total triglycerides. Am J Med Tech 35: 93-102, 1969

11. Siegel S: Nonparametric Statistics for the Bchavioral Sciences pp. 123 229, NY McGraw-Hill Book Co, 1956

12. Nayman C, German O, Akgun N: A preliminary investigation on the correlation between the blood cholesterol levels and the physical fitness. Spor Hekim 2:27-34, 1967. From the abstract in J Sports Med Phys Fit 11: 126, 1970

13. Akgun N, Oxgonul H, German O, Kocaturk E: About the relationship between serum cholesterol levels and physical fitness of men. Spor Hekim 4: 43 47, 1969. From the abstract in J Sports Med Phys Fit 11: 127-128, 1970

14. McDonough JR, Kusumi F, Bruce RA: Variations in maximal oxygen intake with physical activity in middle-aged men. Circulation 41: 743-751, 1970

15. Grimby G, Wilhelmsen L, Bjorntorp P, Saltin B, Tibblin G: Habitual physical activity; aerobic power and blood lipids. In Muscle Metabolism during Exercise Pernow B, Saltin B, (Eds). pp. 469-481, Plenum Press, 1971

16. Shane SR: Relation between serum lipids and physical condition. Am J Cardiol 18: 540-543, 1966

17. Skinner JS Benson H, McDonough JR, Haimes CG: Social status, physical activity, and coronary proneness. J Chron Dis 19: 773-83. 1966

18. Zauner CW, Swenson EW: Physical training and physical performance in relation to blood lipid levels and pulmonary function. Am Corr Ther J 21: 159-165, 1967

19. Cooper KH, Pollock ML, Martin RP, White SR, Linnerudac, Jackson A: Physical fitness levels vs selected coronary risk factors. JAMA 236: 166-169, 1976

20. Allard C, Goulet C: Working capacity, blood lipids, and uric acid. Sartryck Ur Forsrarsmedicin 3: 203-205, 1967

21. Melesis CA: Prediction of serum cholesterol. Proceedings of the Convention of the American Association for Health, Physical Education and Recreation 71, 1969

22. Marley WP, Smith WE, Linnerud AC, Sonner WH, Royster CL Chasson AL: A five-year study of uric acid, cholesterol, and selected fitness variables in professional men. Carolina Med J 35: 730-735, 1974

23. Hernberg S: Correlation between physical working capacity and serum cholesterol in leading businessmen. Physical Activity and the Heart Karvonen, MJ Barry AJ, (Eds). Springfield, Ill, CC. Thomas, 249-256, 1967

24. Hernberg S: Serum cholesterol and capacity for physical work. Lancet 2: 441-443, 1964

25. Oberman A, Lane NE, Mitchell RE, Graybiel A: The Thousand Aviator Study: Distributions and Intercorrelations of Selected Variables Monograph 12, Pensacola, FL: U.S.A. Naval Aerospace Medical Institute, 1965

26. Lopez SA, Arroyave G: Relationships between physical exercise index and serum cholesterol. Fedn Proc Fedn Am Socs exp Biol 30: 645, 1971

27. Gyntelberg F, Ohlsen K: Physical fitness and serum cholesterol in Copenhagen males aged 40-59. Scand J clin Lab Invest 32: 211-216, 1973

28. Salzman SH, Hellerstein HK, Feil GH, Marik S: Serum cholesterol and capacity for physical work of middle-aged sedentary males. Circulation 36: 229, 1967

29. Montoye HJ, Block WD, Keller JB, Willis PW 3: Fitness, fatness and serum cholesterol: An epidemiologic study in an entire community. Res Quart, 47: 400-408, 1976

30. Lopez SA, Vial R, Balart L, Arroyave G: Effect of exercise and physical fitness on serum lipids and lipoproteins. Atherosclerosis 20: 1-9, 1974

31. Young RJ, Ismail AH: Relationships between anthropometric, physiologic, biochemical, and personality variables before and after a four month conditioning program. J Sports Med Phys Fit 11: 267-276, 1976

32. Ekelund, L-G, Olsson AG: Studies in asymptomatic primary hyperlipidaemia. Acta Med scand 197: $487-494,1975$ 